\title{
Correction: The Utilisation of Reduced Kinetics by Local Self-Similarity Tabulation Approach in 3D Turbulent Reactive Flow Simulation with LES and TPDF
}

\author{
Serdar Guryuva ${ }^{1}$ (D) $\cdot$ Hasan Bedir ${ }^{1}$
}

Published online: 23 September 2021

(c) Springer Nature B.V. 2021

\section{Correction to: Flow, Turbulence and Combustion https://doi.org/10.1007/s10494-021-00260-3}

The authors regret that in the Acknowledgement section Dr. Panagiotis Kourdis was inadvertently not mentioned as the co-author of the publications on which this study is based. The article is therefore corrected as follows:

The Conflict of Interest section should be removed, since the authors do not have any competing or conflicting interests with Dr. Bellan and Dr. Kourdis.

The Acknowledgement section should read:

The present study is based on the publications of Dr. Josette Bellan from the Jet Propulsion Laboratory of California Institute of Technology and Dr. Panagiotis Kourdis from IBM Research, Almaden.

The authors would like to acknowledge the support from Bogazici University under grant number 11A06D1. Computing resources used in this work were provided by the Turkish National Center for High-Performance Computing (UYBHM) under Grant Number 1001202011. Special thanks are extended to Prof. Dr. Kunt Atalık and Prof. Dr. A. Erhan Aksoylu for their support and advice.

The original article can be found online at https://doi.org/10.1007/s10494-021-00260-3.

Serdar Guryuva

serdarguryuva@gmail.com

Hasan Bedir

bedirhas@boun.edu.tr

1 Mechanical Engineering Department, Bogazici University, Istanbul, Turkey 